\title{
Rheological Characteristics, Thermodynamics, and Morphologies of Polyethylene Binary Blends
}

\author{
Satoru HosODA and Yuji GoTOH \\ Chiba Research Laboratory, Sumitomo Chemical Co., Ltd., \\ Anesakikaigan 5-1, Ichihara-shi, Chiba 299-01, Japan
}

(Received May 25, 1987)

\begin{abstract}
Steady and dynamic melt viscoelasticity, thermodynamics and morphologies were investigated for linear/linear, branched/branched and linear/branched polyethylene blends. Elastic parameters such as the first normal stress difference $\left(P_{11}-P_{22}\right)$ and storage modulus $\left(G^{\prime}\right)$ have large positive dependence on blend composition and show much higher values than those calculated from the following mixing rule which is valid for linear/linear and branched/branched polyethylene blends at a constant shear rate: $P^{0.4}=w_{1} P_{1}{ }^{0.4}+w_{2} P_{2}{ }^{0.4}$. The deviation from this mixing rule is sensitive to shear rate in case of linear/branched polyethylene blends. The FloryHuggins interaction parameter, $\chi_{12}$, which is calculated from melting temperature depression suggests these blends to be miscible. The rate of crystallization and the spherulite size of linear polyethylene are remarkably reduced by mixing a small amount of branched polyethylene. From observations by SEM and TEM, it has been proved that linear- and branched-polyethylenes in the blend are well mixed in sub-micron order though they separate from each other during crystallization to make their individual lamellar crystals.

KEY WORDS Linear Low-Density Polyethylene / High-Pressure LowDensity Polyethylene / High-Density Polyethylene / Binary Blends / Melt Viscoelasticity / Mixing Rule/ Thermodynamics / Crystallization Rate / Spherulite / Lamellar Morphology /
\end{abstract}

Linear low-density polyethylene (L-LD) has been produced all over the world for about the last 10 years and gradually replaced conventional high-pressure low-density polyethylene (HP-LD) through its superior mechanical and thermal properties. However, a number of LLD is really used as a blend with HP-LD to improve a manufacturing processability and to improve the properties of products. The socalled necking phenomenon which is a constriction of a polymer extruded from a flat die is one of the severe problems in lamination (a film coating) manufacturing of L-LD. This phenomenon is said to be related to the elastic property of a polymer, and in the case of HPLD the polymer having a wide molecular weight distribution and many long chain branchings is generally used as a lamination grade. In the case of L-LD and high-density polyethylene (HD), it is known that necking can be less remarkable in the blends with HPLD. In the manufacturing of a L-LD blown film, it is also well known that the addition of a small amount of HP-LD has a remarkable efficiency to improve both the processing stability and optical properties of a film, and a considerable amount of L-LD blown film is now commercially produced as a blend with HP-LD. Here the processing stability described above is mainly for the bubble shape stability. The stable bubble which makes the high-quality film of an uniform thickness is obtained under very limited operating conditions in case of L-LD and HD contrary to rather wide conditions for HPLD, as reported by Kanai et al. ${ }^{1}$ The differ- 
ence of the bubble stability between L-LD and HP-LD is considered to be due to the difference of the melt tension of the bubble. From these points of view, the melt viscoelastic properties of L-LD/HP-LD blend should be investigated to understand the origin of the improvement effect on the processability of some L-LD manufacturings.

Further, the second point of our interest for this binary blend is the improvement of optical properties of a blown film. The transparency

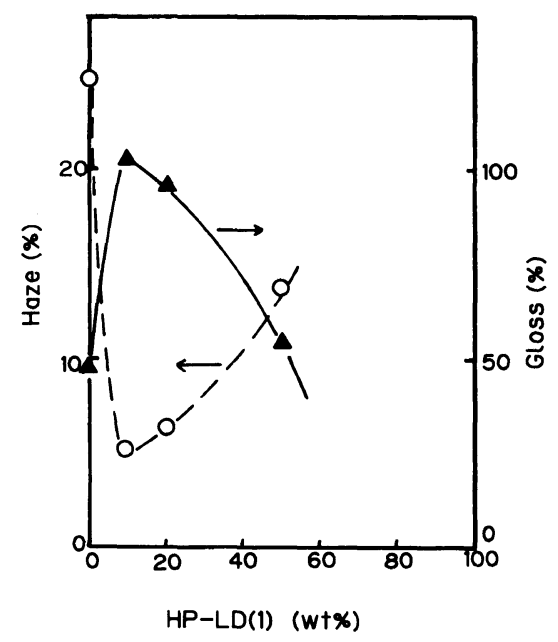

Figure 1. The optical properties of the blown film of LLD(1)/HP-LD(1) blend vs. blend composition. and gloss of a L-LD film are drastically improved by the addition of a small amount of HP-LD as shown in Figure 1. It was reported $^{2,3}$ that the transparency of a L-LD blown film is governed generally not of the internal but the external haze which is caused by surface roughness, and the control of a crystallization rate during processing is the most important for the optical properties of a film. However, what kinds of changes in the crystallization rate and the crystal size are caused by the addition of HP-LD are still unclear. In this paper, to understand the phenomena in blown film extrusion and elucidate the origin of the improvement effects caused by mixing HP-LD on a manufacturing processability and the optical properties of LLD blown film, some basic approaches for various polyethylene binary blends were adopted from the viewpoints of melt rheology, thermodynamics and morphology.

\section{EXPERIMENTAL}

\section{Samples}

HP-LD, L-LD, and HD samples used in this work are commercial grades of Sumitomo Chemical Co., Ltd. Ethylene-butene type LLDs were used here (Table I). Quantitative

Table I. Molecular characteristics of polyethylene samples

\begin{tabular}{ccccccc}
\hline Samples & $\begin{array}{c}\text { Melt index } \\
\mathrm{g} / 10 \mathrm{~min}\end{array}$ & $\begin{array}{c}\text { Density } \\
\mathrm{g} / \mathrm{cm}^{\mathrm{b}}\end{array}$ & $\begin{array}{c}\bar{M}_{n}^{\mathrm{c}} \\
\times 10^{4}\end{array}$ & $\begin{array}{c}\bar{M}_{w}^{\mathrm{c}} \\
\times 10^{4}\end{array}$ & $\begin{array}{c}\bar{M}_{z}^{\mathrm{c}} \\
\times 10^{4}\end{array}$ & $\begin{array}{c}\bar{n}_{w}^{\mathrm{d}} \\
\text { HP-LD(1) }\end{array}$ \\
HP-LD(2) & 7 & 0.920 & 2.6 & 65.4 & 475 & 14.5 \\
HP-LD(3) & 7 & 0.920 & 4.9 & 11.8 & 16 & 0.43 \\
HP-LD(4) & 2 & 0.920 & 2.8 & 97.4 & 887 & 48.0 \\
HP-LD(5) & 7 & 0.925 & 4.6 & 15.5 & 24 & 0.39 \\
L-LD(1) & 1 & 0.920 & 3.0 & 66.6 & 614 & 17.4 \\
L-LD(2) & 4 & 0.917 & 4.1 & 13.1 & 27 & - \\
L-LD(3) & 7 & 0.930 & 2.4 & 8.4 & 18 & - \\
HD(1) & 0.9 & 0.920 & 1.5 & 4.8 & 16 & - \\
\hline
\end{tabular}

a Measured at $190^{\circ} \mathrm{C}$.

b Measured at $23^{\circ} \mathrm{C}$.

c Number average $\left(\bar{M}_{n}\right)$, weight average $\left(\bar{M}_{w}\right)$, and $Z$-average $\left(\bar{M}_{z}\right)$ molecular weight determined by means of GPC combined with low-angle laser light scattering (GPC-LALLS).

${ }^{d}$ Weight average number of long-chain branching points per molecule (see the text). 
Table II. [ $[\eta]$ of L-LD, HP-LD, and their mixtures

\begin{tabular}{lc}
\hline & {$[\eta]$} \\
\cline { 2 - 2 } & $\mathrm{dlg}^{-1}$ \\
\hline L-LD(1) & 1.764 \\
HP-LD(1) & 0.973 \\
Brabender-mixed & 1.353 \\
Solution-mixed $^{\mathrm{b}}$ & 1.354 \\
\hline
\end{tabular}

a Measured in tetrahydronaphthalene at $135^{\circ} \mathrm{C}$ (2,6-di- $t$ butylphenol, $0.2 \%$ ).

b $\mathrm{L}-\mathrm{LD}(1)$ and HP-LD(1) were mixed (50/50) with a Brabender Plasticorder at $160^{\circ} \mathrm{C}$ for $5 \mathrm{~min}$ at $60 \mathrm{rpm}$.

c The above sample pellets of equivalent weight were solved in hot tetrahydronaphthalene, precipitated from methyl alcohol, and then dried in vacuo at $60^{\circ} \mathrm{C}$.

determination of the molecular weight and number of long-chain branching of the samples was carried out by use of GPC-LALLS. The number of branching points per molecule $\left(\bar{n}_{w}\right)$ was determined following the method proposed by Drott, ${ }^{4}$ taking the $b$-value as $0.9^{5}$ in the equation: $g^{\prime}=g^{\mathrm{b}}\left(g^{\prime}=[\eta]_{\mathrm{br}} /[\eta]_{1}, g=\right.$ $\left\langle S^{2}\right\rangle_{\mathrm{br}} /\left\langle S^{2}\right\rangle_{1}$ ). Two kinds of PE pellets at a desired blend ratio were mixed mainly with a Brabender Plasticorder at $160^{\circ} \mathrm{C}$ for 5 minutes at $60 \mathrm{rpm}$. No remarkable change in structure occurred under this condition, judging from the intrinsic viscosity of the mixture made by two different methods as shown in Table II. A blown film was manufactured with a Tomi IFA 600-50 screw extruder with annular blown film die. The extrusion temperature was $180^{\circ} \mathrm{C}$ at the die slit and the extrusion rate was $15 \mathrm{kgh}^{-1}$. The optical properties (haze and gloss) were measured following JIS K7105. Rheological Measurement: A Rheometrics Mechanical Spectrometer Model 605 was used to measure both the dynamic and the steady viscoelastic properties at $140^{\circ} \mathrm{C}$ over the angular frequency and shear rate ranges of $10^{-2}-10^{2} \mathrm{~s}^{-1}$. The samples were melt-pressed to sheets of $2.50 \mathrm{~cm}$ in diameter and $2 \mathrm{~mm}$ in thickness. Rheological measurement was carried out by using a cone/plate type fixture. Thermal Analysis: Melting temperature and crystallization rate of the blend were measured using a Perkin Elmer Differential Scanning Calorimeter (DSC), Model 2. A 5-9 mg specimen was placed in a sealed aluminum pan, heated from $30^{\circ} \mathrm{C}$ to $150^{\circ} \mathrm{C}$ at $80^{\circ} \mathrm{Cmin}^{-1}$, held for 5 minutes, then cooled down to $30^{\circ} \mathrm{C}$ and the endothermic curve was measured at a heating rate of $10^{\circ} \mathrm{C} \mathrm{min}^{-1}$. The equilibrium melting temperature of the blend was determined from a series of melting temperatures of the sample crystallized isothermally in DSC at various temperatures. The crystallization rate of the blend was measured by the DSC exothermic curve in the isothermal crystallization, and was expressed by the reciprocal time that the system reaches the half degree of the whole crystallization. Morphology: The lamellar morphology was observed by transmission electron-microscopy. The extruded strand from a Capillary Rheometer was quenched in a liquid nitrogen bath installed just under the exit of the die, and it was stained by using both chlorosulfonic acid and uranyl acetate according to $\mathrm{Kanig}^{6}$ and then sectioned at room temperature by ultramicrotome. The hot-press molded sample sheet was etched by trichloroethylene at $80^{\circ} \mathrm{C}$ for $5 \mathrm{~min}$, and the etched surface was observed by scanning electron-microscopy. The small angle laser light scattering (SALS) pattern was measured under $H_{\mathrm{v}}$ polarization and the average radius of the spherulite was calculated from the scattering angle of the maximum light intensity.

\section{RESULTS AND DISCUSSION}

\section{Melt Rheology}

Storage modulus $\left(G^{\prime}\right)$, loss modulus $\left(G^{\prime \prime}\right)$, and absolute value of complex dynamic viscosity $\left(\eta^{*}\right)$, first normal stress difference $\left(P_{11}-P_{22}\right)$ and steady shear viscosity $(\eta)$, for the blends of L-LD/L-LD, HP-LD/HP-LD, and L-LD/HP-LD were measured. The parameters except $G^{\prime \prime}$ are presented as functions of the angular frequency $(\omega)$ and the shear 
rates $(j)$ in Figures $2-7$. It is interesting that the L-LD/HP-LD blend series clearly show a different dependence of these parameters on $\omega$ or $\dot{\gamma}$, especially at low frequencies and shear rate compared to L-LD/L-LD and HP-LD/HP-LD blends (Figures 4 and 7). $\eta$

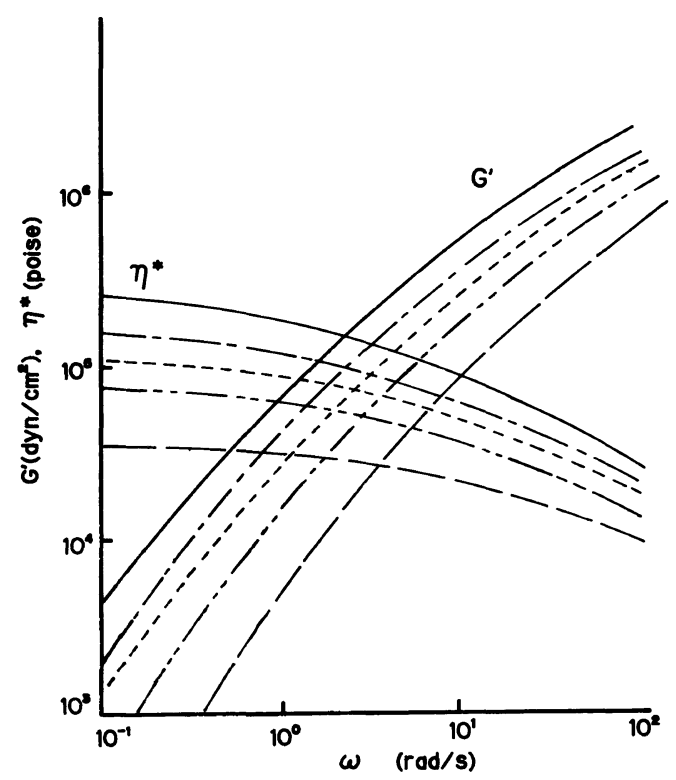

Figure 2. $G^{\prime}$ and $\eta^{*} v s$. $\omega$ at $140^{\circ} \mathrm{C}$ for $\mathrm{L}-\mathrm{LD}(1) / \mathrm{L}-$ $\mathrm{LD}(3)$ blends. L-LD(1)/L-LD(3): -,$- 100 / 0$; 70/30; - - , 50/50; - - $30 / 70 ;-\longrightarrow, 0 / 100$. and $P_{11}-P_{22}$ are expressed as functions of shear stress $\left(P_{12}\right)$ in Figures 8 and 9 , respectively. $\eta$ for L-LD/L-LD blend changes between $\eta$ of two component L-LDs depending on the blend composition; however, L-LD/HP-LD blend shows a higher $\eta$ than the components in the wide range of shear stress. Plots of $P_{11}-P_{22}$ vs. $P_{12}$ for LLD/L-LD blend showed a single line independent on the blend composition. Nevertheless, the same plots for L-LD/HP-LD blend showed a different relation. Since $P_{12}$ and $P_{11}-P_{22}$ or $G^{\prime \prime}$ and $G^{\prime}$ may be interpreted respectively, as a measure of dissipated energy and that stored in the molecules during the shearing deformation, the ratio of the stored energy and that dissipated is expected to be independent of the blend composition as long as the molecular structure of the component polymer is the same. This point of view indicates that the difference of $P_{11}-P_{22}$ between HP-LD and L-LD at the same $P_{12}$ would be mainly due to the difference of molecular structure classified by long-chain branching though the effect of molecular weight distribution should be considered for further discussion. ${ }^{7}$ Viscoelastic parameters measured for L-LD/HP-LD blend at a constant shear rate

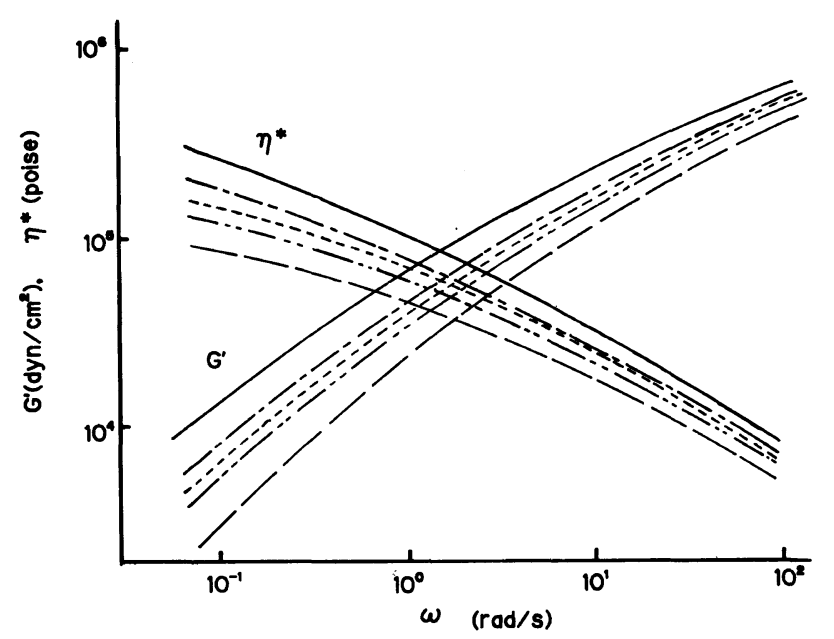

Figure 3. $G^{\prime}$ and $\eta^{*} v$ s. $\omega$ at $140^{\circ} \mathrm{C}$ for $\mathrm{HP}-\mathrm{LD}(1) / \mathrm{HP}-\mathrm{LD}(3)$ blends. $\mathrm{HP}-\mathrm{LD}(3) / \mathrm{HP}-\mathrm{LD}(1):-, 100 / 0$; $\longrightarrow, 70 / 30 ;----, 50 / 50 ;--\ldots, 30 / 70 ;-\ldots, 0 / 100$. 


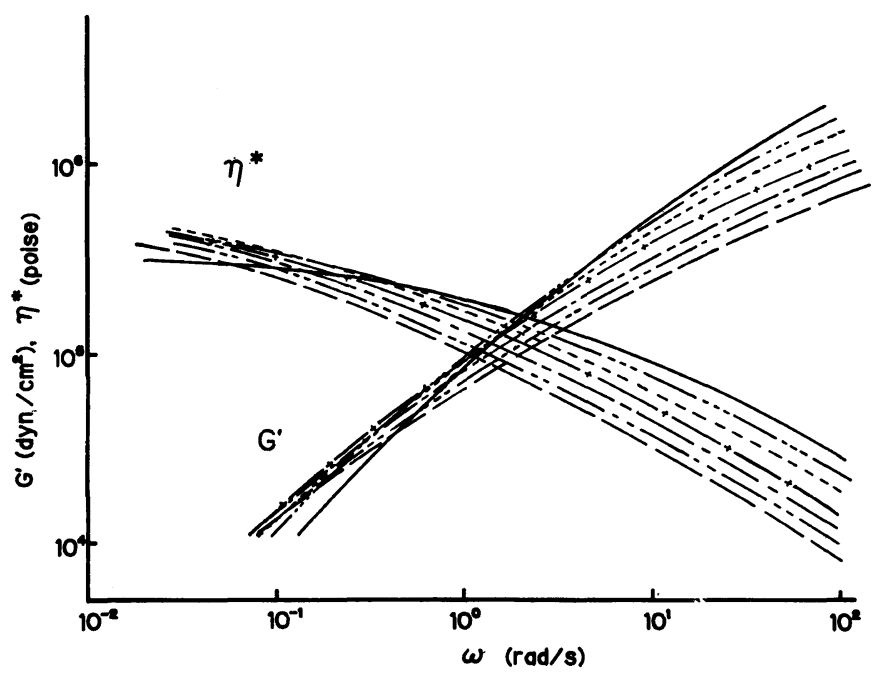

Figure 4. $G^{\prime}$ and $\eta^{*} v s . \omega$ at $140^{\circ} \mathrm{C}$ for $\operatorname{L-LD}(1) / \mathrm{HP}-\mathrm{LD}(3)$ blends. $\mathrm{L}-\mathrm{LD}(1) / \mathrm{HP}-\mathrm{LD}(3)$ :,$- 100 / 0$;

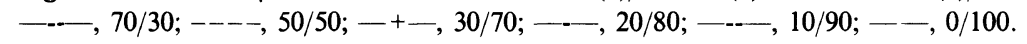

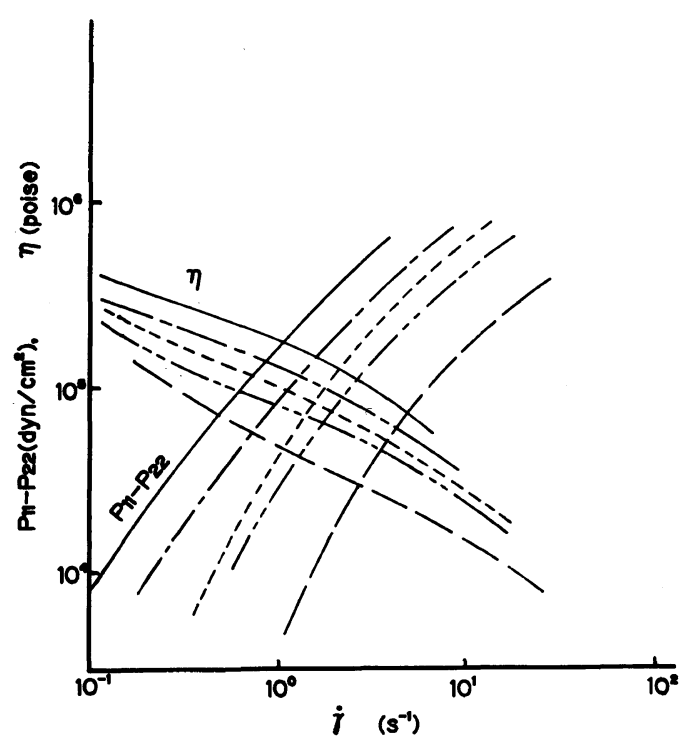

Figure 5. $\quad P_{11}-P_{22}$ and $\eta v s . \dot{\gamma}$ at $140^{\circ} \mathrm{C}$ for $\mathrm{L}-\mathrm{LD}(1) / \mathrm{L}-$ LD(3) blends. L-LD(1)/L-LD(3): —, 100/0; —$70 / 30 ;---, 50 / 50 ;-\cdots, 30 / 70 ;-\ldots, 0 / 100$.

$\left(\dot{\gamma}=10^{-1} \mathrm{~s}^{-1}\right)$ are plotted as a function of blend composition in Figure 10. Every parameter shows a positive deviation from the following log-additivity rule,

$$
\log P_{\mathrm{b}}=w_{1} \log P_{1}+w_{2} \log P_{2}
$$

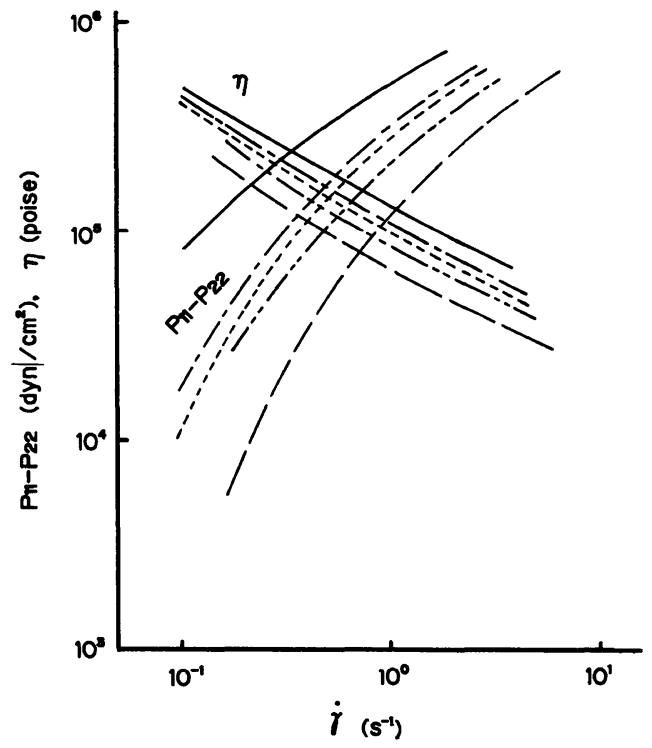

Figure 6. $\quad P_{11}-P_{22}$ and $\eta v s . \dot{\gamma}$ at $140^{\circ} \mathrm{C}$ for $\mathrm{HP}-\mathrm{LD}(1) /$ HP-LD(3) blends. HP-LD(3)/HP-LD(1): — , 100/0; $-\_, 70 / 30 ;----, 50 / 50 ;-\ldots, 30 / 70 ;-\ldots, 0 / 100$.

where $P$ is a viscoelastic parameter, $w$ the weight faction, and subscripts b, 1 , and 2 , stand for the blend, component polymers 1 and 2, respectively. It can be easily seen from Figure 9 that the plot of $P_{11}-P_{22} v s$. blend composition at a constant shear stress $\left(P_{12}\right)$ also shows a 
positive deviation from the log-additivity rule for L-LD/HP-LD blend. The same kind of compositional dependences of some viscoelastic parameters for polyethylene blends have also been reported ${ }^{8-11}$ and some mixing rules for melt viscosity were proposed. Then a mixing rule for elastic parameters was examined for $\mathrm{L}-\mathrm{LD}(1) / \mathrm{L}-\mathrm{LD}(2)$ and $\mathrm{HP}-\mathrm{LD}(1) / \mathrm{HP}-$ $\mathrm{LD}(2)$ blends, and it was found that $G^{\prime}$ and $P_{11}-P_{22}$ completely fit the following equation,

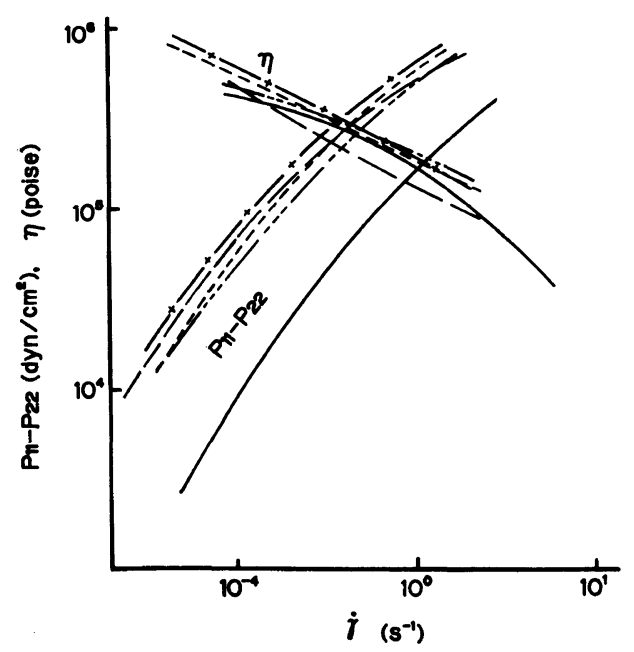

Figure 7. $P_{11}-P_{22}$ and $\eta v s . \dot{\gamma}$ at $140^{\circ} \mathrm{C}$ for $\mathrm{L}-\mathrm{LD}(1) /$ HP-LD(3) blends. L-LD(1)/HP-LD(3): —, 100/0; .$---70 / 30 ;----, 50 / 50 ;-+-, 30 / 70 ;-\ldots, 20 / 80$; , 10/90; - - 0/100.

$$
P_{\mathrm{b}}^{0.4}=w_{1} P_{1}^{0.4}+w_{2} P_{2}^{0.4}
$$

where $P$ is $G^{\prime}$ or $P_{11}-P_{22}$ and the other notations are the same in eq 1 . This mixing rule is also applicable to the other blend samples of HP-LD/HP-LD, L-LD/L-LD, and L-LD/HD as shown in Figure 13, where the longitudinal axis expresses the ratio of $P_{11}-$ $P_{22}$ of the blend to that calculated from eq 2 . Furthermore, this rule seems to be valid independent of the shear rate for these blends as shown in Figure 14.

As for the melt viscosity of the homologous polymer blend, it is well known that the following mixing rule is applicable. ${ }^{12}$

$$
\eta_{\mathrm{b}}{ }^{n}=\sum w_{\mathrm{i}} \eta_{\mathrm{i}}{ }^{n}
$$

It might be reasonable to take $n$ as around 0.4 for the melt viscosity of the blends studied here, considering the dependence of viscosity on weight-average molecular weight $\left(\bar{M}_{w}\right)$ shown in eq 4 , and the dependence of $M_{w}$ on weight fraction and $\bar{M}_{w}$ of the components.

$$
\eta \propto \bar{M}_{w^{\prime}}{ }^{3.5}
$$

In case of eq 2 , it would be better to consider that the 0.4 power is just a fitting parameter obtained experimentally, because we cannot find an appropriate relationship having a physical meaning between elastic parameters and weight-average molecular weight. Blends
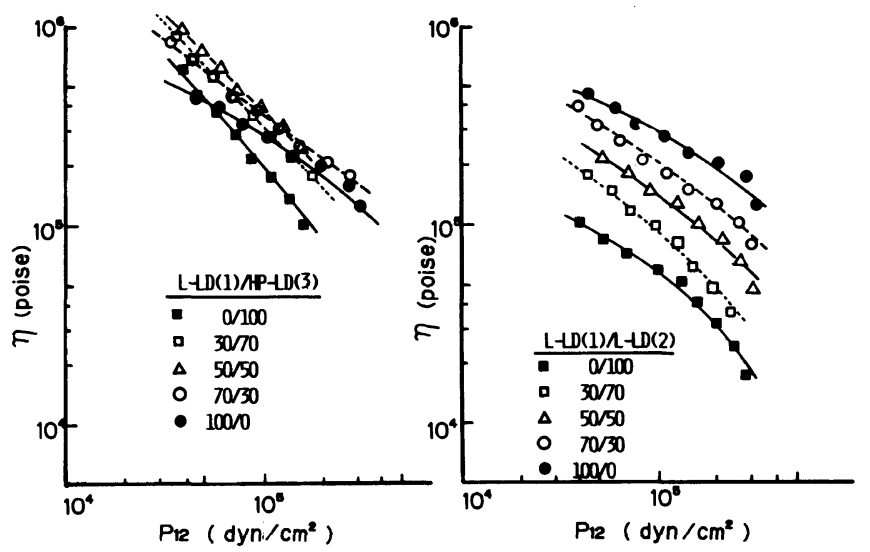

Figure 8. $\eta$ vs. $P_{12}$ at $140^{\circ} \mathrm{C}$ for $\mathrm{L}-\mathrm{LD}(1) / \mathrm{HP}-\mathrm{LD}(3)$ blends (left) and $\mathrm{L}-\mathrm{LD}(1) / \mathrm{L}-\mathrm{LD}(2)$ blends (right). 

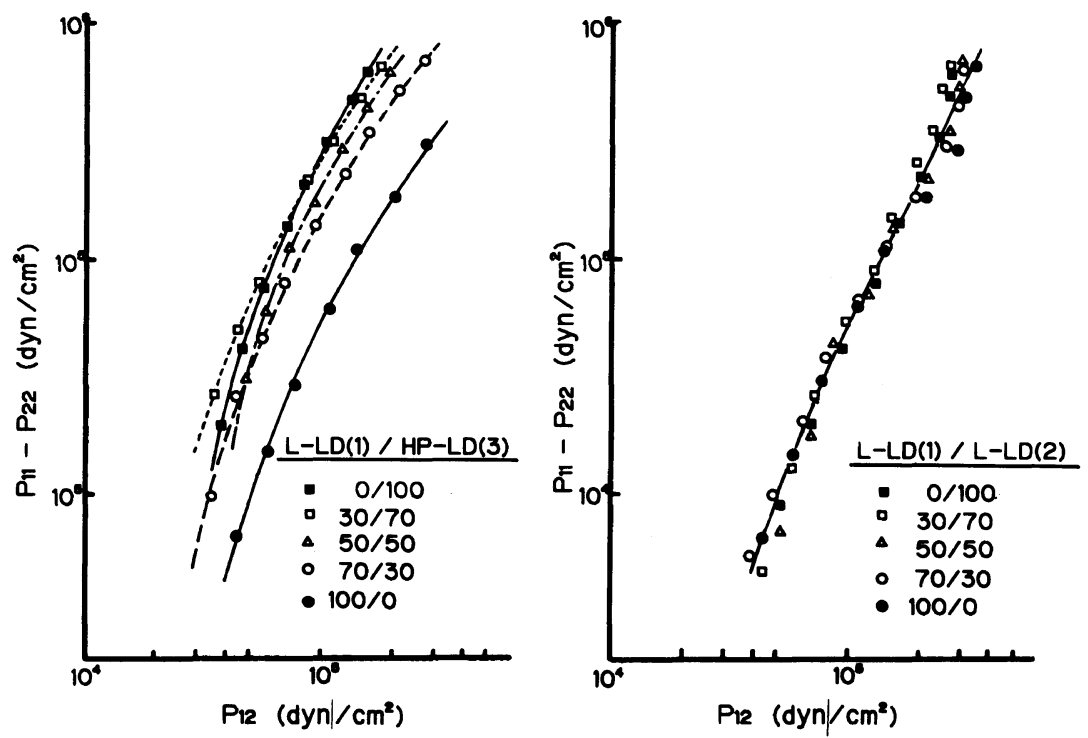

Figure 9. $P_{11}-P_{22}$ vs. $\dot{\gamma}$ at $140^{\circ} \mathrm{C}$ for $\mathrm{L}-\mathrm{LD}(1) / \mathrm{HP}-\mathrm{LD}(3)$ blends (left) and $\mathrm{L}-\mathrm{LD}(1) / \mathrm{L}-\mathrm{LD}(2)$ blends (right).
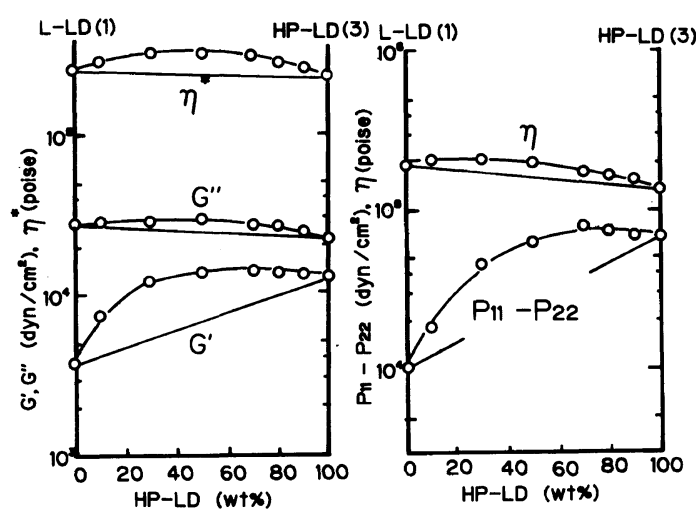

Figure 10. Compositional dependence of viscoelastic parameters for $\mathrm{L}-\mathrm{LD}(1) / \mathrm{HP}-\mathrm{LD}(3)$ blends at a constant frequency $\left(\omega=10^{-1} \mathrm{rad} \cdot \mathrm{s}^{-1}\right)$ and shear rate $(\dot{\gamma}=$ $\left.10^{-1} \mathrm{~s}^{-1}\right)$ at $140^{\circ} \mathrm{C}$.

of linear and branched polyethylene (L-LD/ HP-LD, HD/HP-LD), however, do not obey the simple mixing rule and have larger values than those calculated from eq 2 as shown in Figure 13 (point No. 1-13). In this case the deviation from the mixing rule increases with decrease of the shear rate (Figure 14), suggesting that the effect of HP-LD on melt-elasticity of the blend appears distinguishably in a range

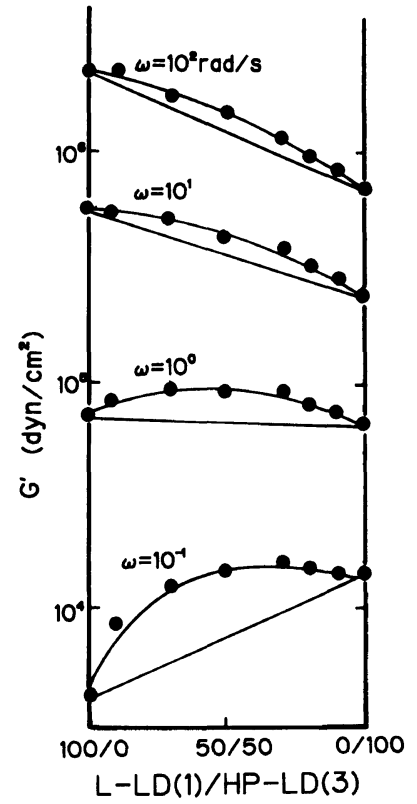

Figure 11. Compositional dependence of $G^{\prime}$ for $\mathrm{L}$ $\mathrm{LD}(1) / \mathrm{HP}-\mathrm{LD}(3)$ blends at various frequency at $140^{\circ} \mathrm{C}$.

of slow relaxation. It can be recognized again from the results shown in Figure 13 that the molecular weight, the molecular weight distribution and the number of long chain branch- 

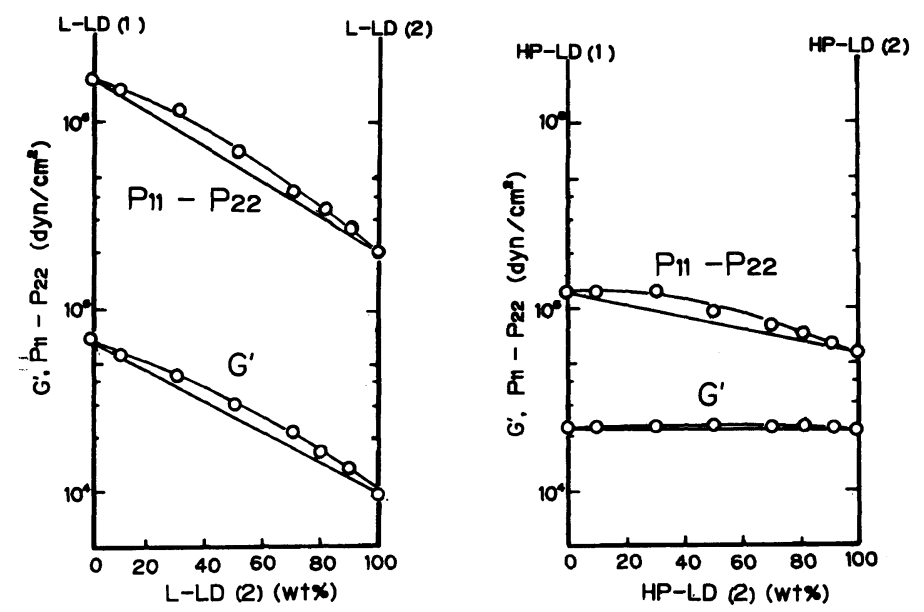

Figure 12. Compositional dependence of viscoelastic parameters for $\operatorname{L-LD}(1) / \mathrm{L}-\mathrm{LD}(2)$ and $\mathrm{HP}-\mathrm{LD}(1)$ / $\mathrm{HP}-\mathrm{LD}(2)$ at a constant frequency $\left(\omega=10^{\circ} \mathrm{rad} \cdot \mathrm{s}^{-1}\right)$ and shear rate $\left(\dot{\gamma}=10^{\circ} \mathrm{s}^{-1}\right)$ at $140^{\circ} \mathrm{C}$.

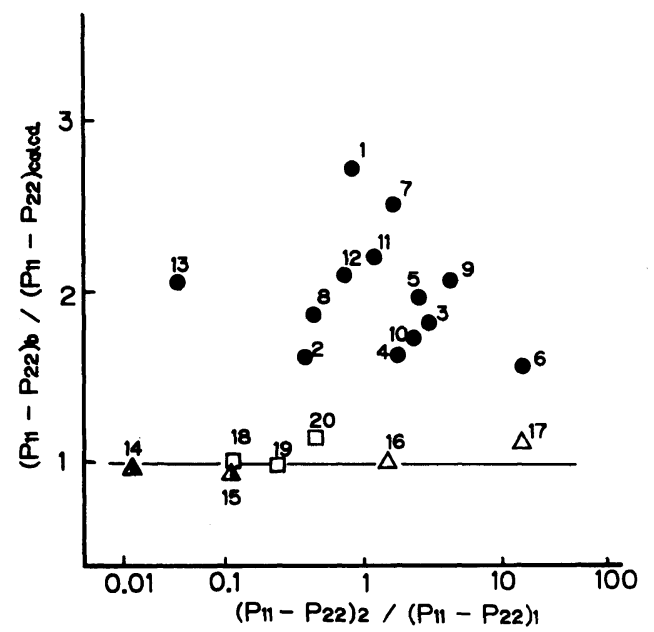

Figure 13. The ratio of $P_{11}-P_{22}$ of the blend to that calculated from the mixing rule (eq 2 in the text) for various polyethylene binary blends $\left(w_{1}=w_{2}=0.5\right)$ at a constant shear rate $\left(\dot{\gamma}=10^{\circ} \mathrm{s}^{-1}\right)$ at $140^{\circ} \mathrm{C}: 1-6 \mathrm{HP}-\mathrm{LD} /$ L-LD(1) blend, (HP-LD) 1(1), 2(2), 3(3), 4(4), 5(5), 6(6, $\mathrm{MI}=1$, density $=0.922) ; 7-12 \mathrm{HP}-\mathrm{LD} / \mathrm{HD}(1)$ blend, (HP-LD) 7(1), 8(2), 9(3), 10(4), 11(5), 12(7, MI=7, density $=0.920), 13$ HP-LD $(8) \quad(\mathrm{MI}=20$, density $=$ $0.918) / \mathrm{HD}(2)(\mathrm{MI}=0.5$, density $=0.951), 14 \mathrm{~L}-\mathrm{LD}(1) /$ L-LD(3), 15 L-LD(1)/L-LD(2), 16 L-LD(1)/HD(1), $17 \mathrm{~L}-\mathrm{LD}(2) / \mathrm{HD}(2) ; 18-20 \mathrm{HP}-\mathrm{LD} / \mathrm{HP}-\mathrm{LD}$ blend, 18 $(2) /(3), 19(1) /(3), 20(1) /(2)$.

ing of HP-LD have a pronounced effect on deviation from the mixing rule. Though the molecular characterization for some of the

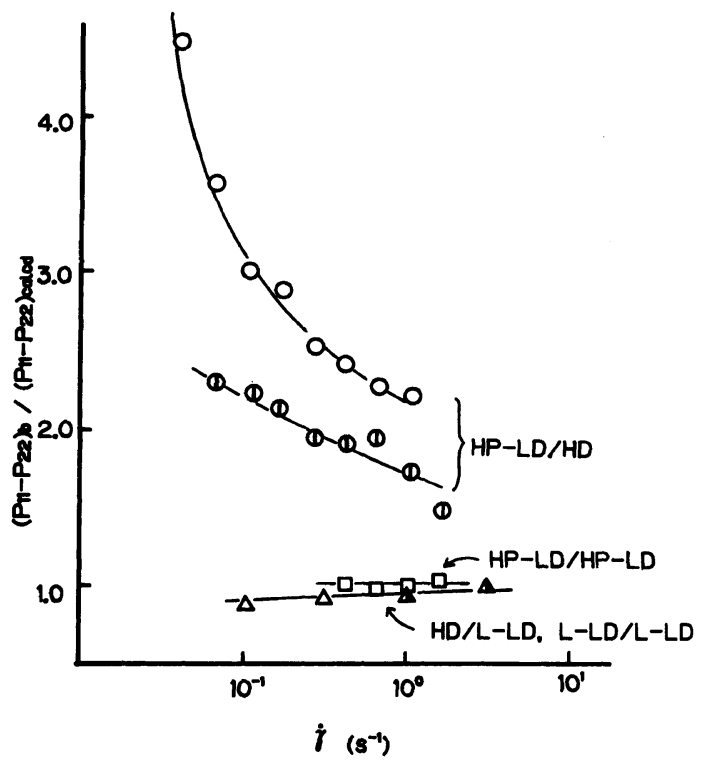

Figure 14. The ratio of $P_{11}-P_{22}$ of the blend to that calculated from the mixing rule (eq 2 in the text) $v s$. shear stress for various polyethylene binary blends $\left(w_{1}=w_{2}=0.5\right)$ at $140^{\circ} \mathrm{C}:(\mathrm{O}) \mathrm{HP}-\mathrm{LD}(1) / \mathrm{HD}(1)$; (1) $\mathrm{HP}-$ $\mathrm{LD}(2) / \mathrm{HD}(1)$; ( $\square) \mathrm{HP}-\mathrm{LD}(2) / \mathrm{HP}-\mathrm{LD}(3) ;(\triangle) \mathrm{L}-\mathrm{LD}(1) /$ $\mathrm{HD}(1) ;(\boldsymbol{\Delta}) \mathrm{L}-\mathrm{LD}(1) / \mathrm{L}-\mathrm{LD}(2)$.

samples remains, generally the larger these structural parameters, the more remarkable is the deviation. A more detailed study of the effects of temperature and the molecular structure of HP-LD has been in progress, ${ }^{13}$ and will 
be published elsewhere.

The unexpected large increase of the meltelasticity of L-LD was achieved by mixing HPLD, and when an appropriate HP-LD is selected this phenomenon should help to solve such problems in L-LD manufacturing as the stability of bubble in blown film extrusion, necking in lamination and the like. Further discussion will require a detailed phenomenological investigation for a temperature gradient and the rate of deformation of melt polyethylene in a real manufacturing process.

\section{Thermodynamics and Morphologies of Poly-} ethylene Blend

The other points of our interest for L-LD/ HP-LD blend besides melt viscoelasticity are thermodynamics and morphology. Because in various practical uses the blends of linear polyethylene (HD, L-LD) and branched polyethylene (HP-LD) are used through their favorable properties connected to the crystal lization. For example, $10-20 \%$ addition of LLD causes a remarkable improvement in the transparency and gloss of a blown film as already shown in Figure 1. This is considered to be closely related to the crystallization rate and crystal size of the blend as being suggested by Ashizawa et al. ${ }^{2}$ They reported that the majority of light scattered from polyethylene films is from the surface and not from the film interior, and the surface scattering results mainly from a crystallization-induced roughness in case of linear polyethylene. On the other hand, though the studies on the morphology, ${ }^{14,15)}$ the thermal and X-ray analyses, ${ }^{16-19}$ and some mechanical properties $^{17,20}$ of polyethylene blends have been reported, detailed studies on the miscibility and on the crystallization rate of the blends are quite few.

First, concerning the miscibility between the linear polyethylene and the branched polyethylene, the Flory-Huggins mutual interaction parameter, $\chi_{12}$ was evaluated from equilibrium melting temperature depression.

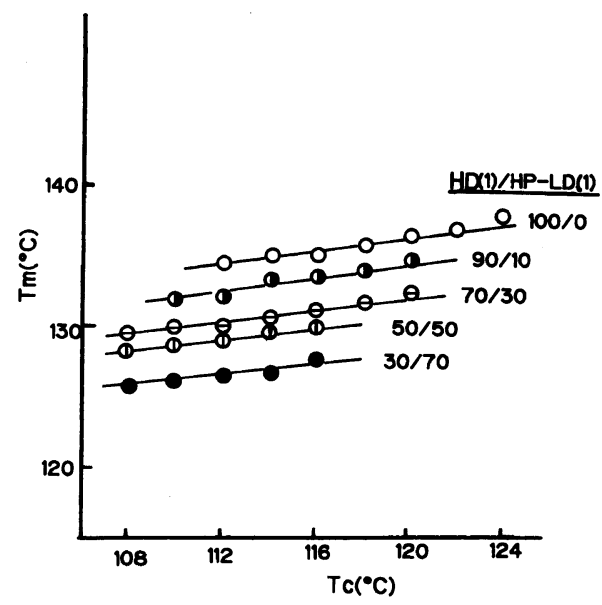

Figure 15. Relationship between crystallization temperature $\left(T_{\mathrm{c}}\right)$ and melting temperature $\left(T_{\mathrm{m}}\right)$ for $\mathrm{HD}(1)$ / HP-LD(1) blends.

The relationship between melting peek temperature $\left(T_{\mathrm{m}}\right)$ and isothermal crystallization temperature $\left(T_{\mathrm{c}}\right)$ for $\mathrm{HD} / \mathrm{HP}-\mathrm{LD}$ blend is shown in Figure 15. For all blend compositions, a linear relationship was observed within the range of the crystallization temperature studied here and this suggests that the following equation is valid,

$$
T_{\mathrm{m}, \mathrm{e}}-T_{\mathrm{m}}=\rho\left(T_{\mathrm{m}, \mathrm{e}}-T_{\mathrm{c}}\right)
$$

where $T_{\mathrm{m}, \mathrm{e}}$ is the equilibrium melting temperature of the blend and $\rho$ the slope (the value of $0.22-0.25$ was obtained from Figure 15). In Figure $16 T_{\mathrm{m}, \mathrm{e}}$ obtained from eq 5 is plotted against the blend composition for $\mathrm{HD}(1) / \mathrm{HP}$ $\mathrm{LD}(1)$ and $\mathrm{HD}(1) / \mathrm{L}-\mathrm{LD}(1) . T_{\mathrm{m}, \mathrm{e}}$ of $\mathrm{HD}$ decreases with increasing concentration of HPLD or L-LD. The melting temperature depression of high-polymer blend can be connected with $\chi_{12}$ as follows, ${ }^{21}$

$$
\frac{1}{T_{\mathrm{m}, \mathrm{e}}}-\frac{1}{T_{\mathrm{m}, \mathrm{e}}^{0}}=-\frac{R V_{1 \mathrm{u}}}{\Delta H_{2 \mathrm{u}} V_{2 \mathrm{u}}} \chi_{12}\left(1-v_{2}\right)^{2}
$$

where $T_{\mathrm{m}, \mathrm{e}}$ is the equilibrium melting temperature of component 2 in the blend, $T_{\mathrm{m}, \mathrm{e}}^{0}$, that of pure component $2, V_{1 \mathrm{u}}, V_{2 \mathrm{u}}$ the molar volume of the components 1 and 2, respectively, $\Delta H_{2 u}$ the heat of fusion per repeating unit, $v_{2}$ the 
volume fraction of component 2. Here $\Delta H_{2 u}$ of HD was experimentally obtained from the relationship between $\Delta H_{\mathrm{m}}$ and $T_{\mathrm{c}}$ (733 $\mathrm{cal} \mathrm{mol}^{-1}$ ). The relationship between $T_{\mathrm{m}, \mathrm{e}}$ of $\mathrm{HD}(1)$ and blend composition was calculated from eq 6 for various values of $\chi_{12}$ and shown in Figure 16. $\chi_{12}$ seems to be the same between two kinds of blends and a value of about -0.08 was obtained in HD rich composition. The negative value of $\chi_{12}$ suggests that these blends are miscible in thermodynamically equilibrium state. Then, the isothermal crystallization rate was investigated using these blends. Figure 17 shows that the crystallization rate of HD component in HD/ HP-LD blend is reduced to half of that of pure HD by the addition of $10 \%$ of HP-LD, while the retardation of crystallization rate is not so remarkable in $\mathrm{HD} / \mathrm{L}-\mathrm{LD}$ blends of minor $\mathrm{L}$ LD composition. Since $T_{\mathrm{m}, \mathrm{e}}$ seems to be the same between two kinds of blend as shown in Figure 16, the degree of super cooling in crystallization at a given temperature $\left(T_{\mathrm{c}}\right)$ would be the same. So the difference in isothermal crystallization rate is considered to be due not to thermodynamic equilibrium but to kinetics. The entanglements between HD molecule and HP-LD molecule of high molecular weight having long relaxation time might be the origin of the remarkable retardation of the crystallization rate in HD/HP-LD blend. This phenomenon was also seen in L-LD(1)/HP$\mathrm{LD}(1)$ blend. The crystallization rate of $\mathrm{L}$ $\mathrm{LD}(1)$ was reduced to half by mixing $10-20 \%$ of HP-LD(1). Then, to study the effects of the reduction of crystallization rate of linear polyethylene on spherulite size, small angle light scattering (SALS) patterns of L-LD/HP-LD blends were measured under $H_{\mathrm{v}}$ condition (Figure 18). All samples had a typical four-leaf clover appearance and this suggests that a well defined spherulite is formed for these blends. The average spherulite radius was calculated from the point of maximum light intensity using the following relation,

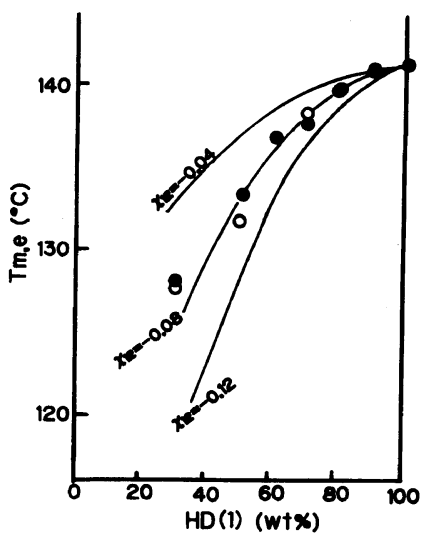

Figure 16. Relationship between the blend composition and an equilibrium melting temperature $\left(T_{\mathrm{m}, \mathrm{e}}\right)$ for $\mathrm{HD}(1) / \mathrm{HP}-\mathrm{LD}(1)(\bigcirc)$ and $\mathrm{HD}(1) / \mathrm{L}-\mathrm{LD}(1)(\bigcirc)$ blends.

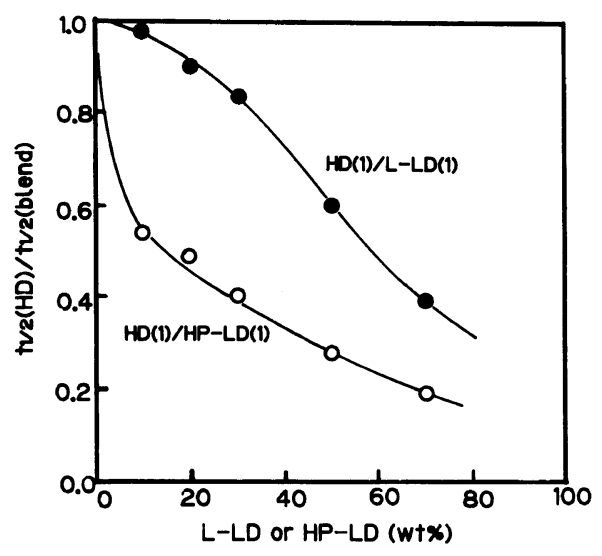

Figure 17. Relation between the blend composition and crystallization rate at $122^{\circ} \mathrm{C}$ for $\mathrm{HD}(1) / \mathrm{L}-\mathrm{LD}(1)$ and $\mathrm{HD}(1) / \mathrm{HP}-\mathrm{LD}(1)$ blends.

$$
\theta_{\max }=2 \sin ^{-1}(\lambda / R)
$$

where $\theta_{\max }$ is the scattering angle of maximum light intensity, $\lambda$ the wave length of the light used $(6328 \AA), R$ the average radius of spherulite. As shown in Figure 19, $R$ of L-LD decreases drastically by mixing only $10 \%$ of HP-LD. This should be due to retardation of the spherulite growing rate and corresponds to the reduction of crystallization rate of linear polyethylene component by mixing HP-LD.

Finally the morphologies of polyethylene blends were investigated. First the surface 


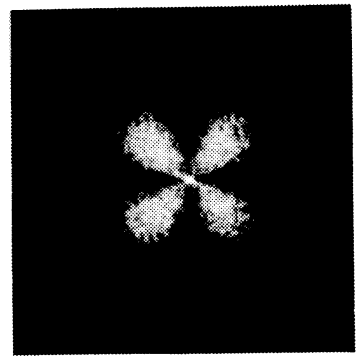

$100 / 0$

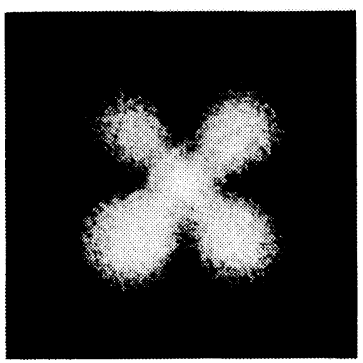

$70 / 30$

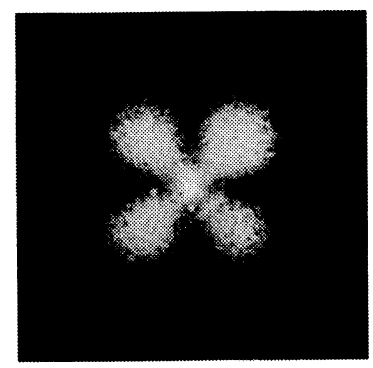

$90 / 10$

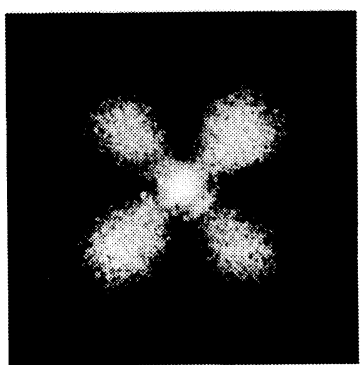

$50 / 50$

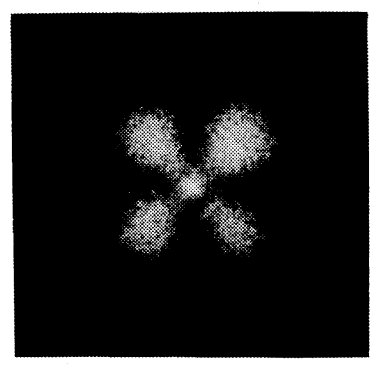

$80 / 20$

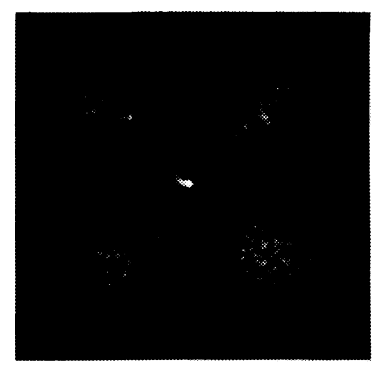

$0 / 100$

L-LD/HP-LD

Figure 18. SALS patterns $\left(H_{\mathrm{v}}\right)$ of $\mathrm{L}-\mathrm{LD}(1) / \mathrm{HP}-\mathrm{LD}(1)$ blends.

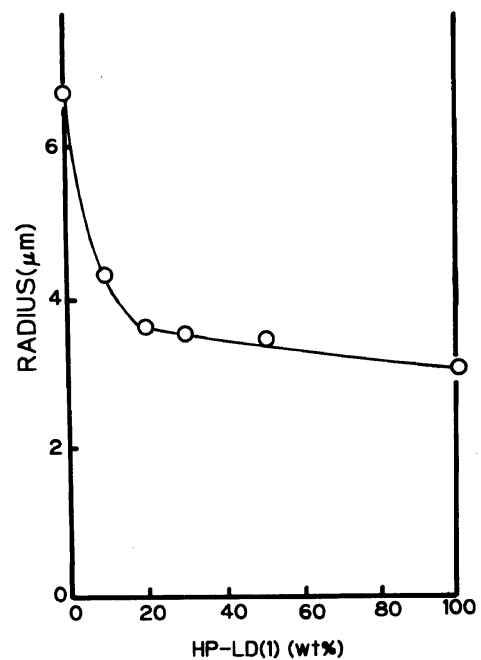

Figure 19. Spherulite radius of $\mathrm{L}-\mathrm{LD}(1) / \mathrm{HP}-\mathrm{LD}(1)$ blends calculated from the SALS patterns.

morphologies of the sample etched by trichloroethylene was observed by scanning electron-microscopy (SEM). The morphologi- cal difference between HD and HP-LD has become apparent by etching at $80^{\circ} \mathrm{C}$ for $5 \mathrm{~min}$. Under this condition, the surface of HP-LD was considerable etched by the solvent and the spherulite-like structure having a diameter of $1-5 \mu \mathrm{m}$ can be found as shown in Figure 21c. The bundle-like crystals randomly oriented are observed at the etched surface of HD (Figure $21 \mathrm{~b}$ ). The surface morphology of HD/HP-LD blend seems to be similar to that of HD and no vigorously etched part can be found. This indicates that no aggromerate of HP-LD in micron order would exist in the blend. Finally, lamellar morphology of the same samples shown above was observed by transmission electron-microscopy (TEM). As already shown in our recent study, ${ }^{22}$ thick (ca. $200 \AA$ ), straight lamellae are characteristic of the HD sample, and the thin (ca. $100 \AA)$, curved lamellae to HP-LD (Figures 21a and b). Both kinds of lamellae are observed disorderly and 


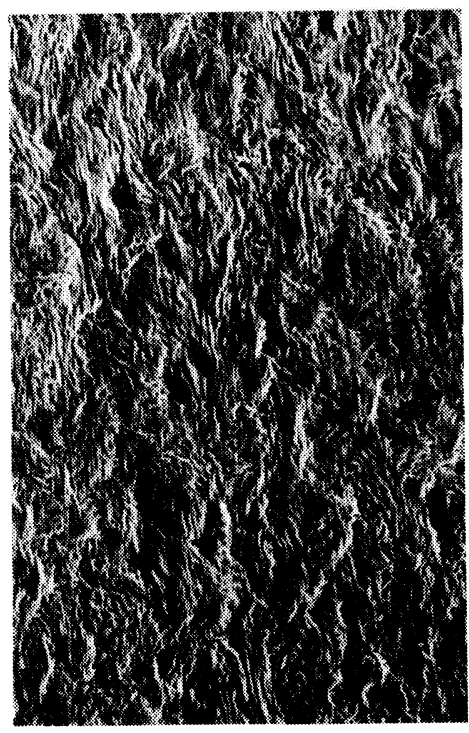

(a)

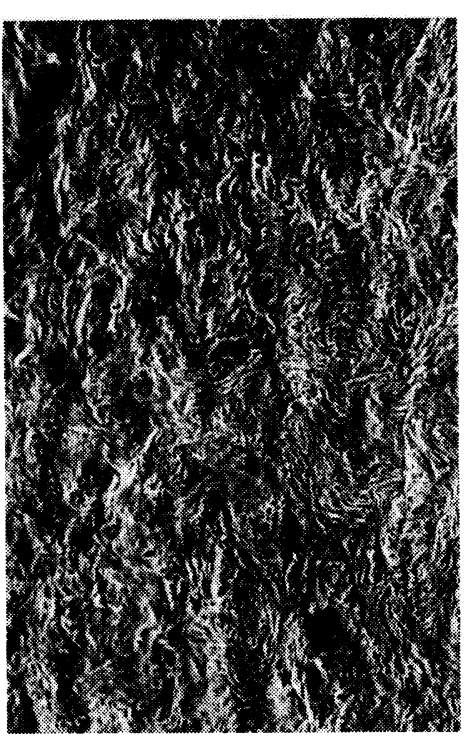

(b)

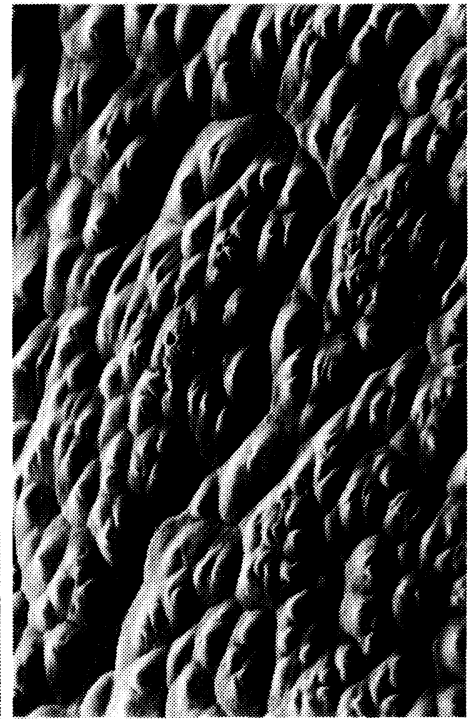

(C) $\overrightarrow{5 \mu \mathrm{m}}$

Figure 20. SEM photographs of trichloroethylene-ethched surface of a) HD(1)/HP-LD(1) blend (70/30), b) $\mathrm{HD}(1)$, and c) HP-LD(1).

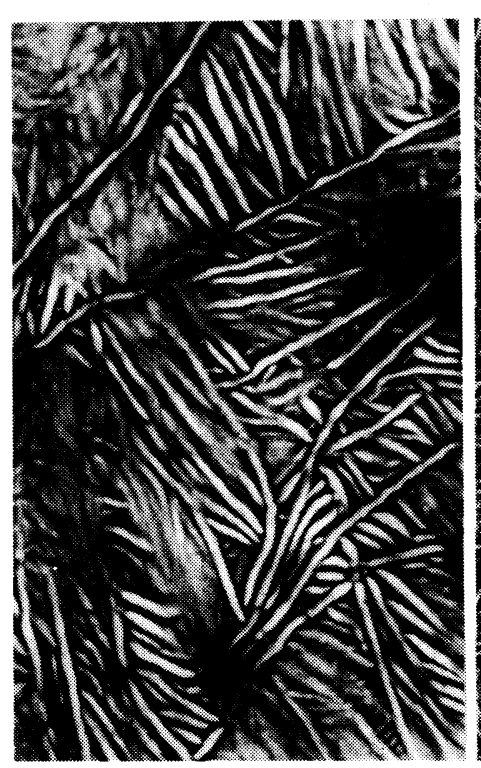

(a)

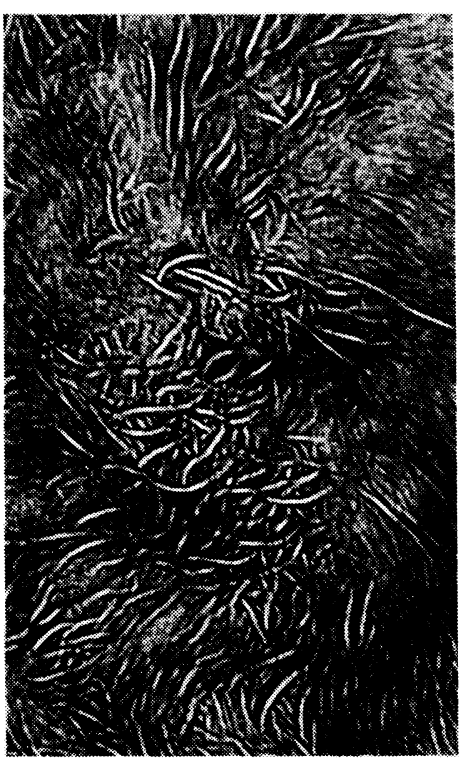

(b)

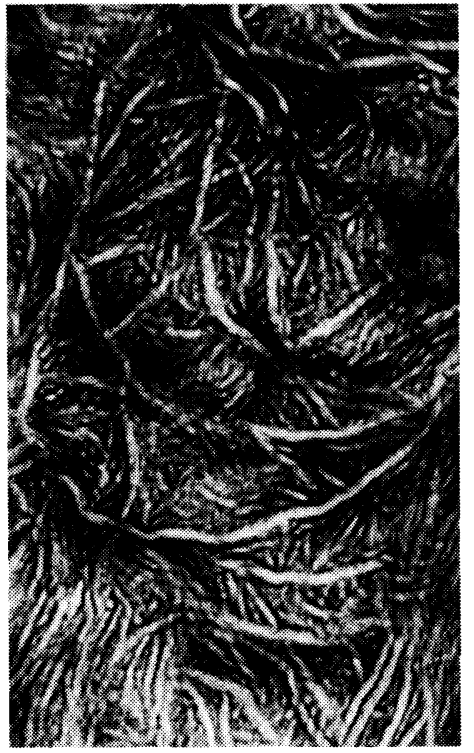

(c)

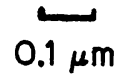

Figure 21. TEM photographs of a) $\operatorname{HD}(1)$, b) $\operatorname{HP}-\operatorname{LD}(1)$, and c) $\operatorname{HD}(1) / \mathrm{HP}-\mathrm{LD}(1)$ blend (30/70). 
interpenetratingly with each other in case of HD/HP-LD (30:70) blend (Figure 21c). This suggests that both polyethylenes are well mixed in a molten state in sub-micron order at least, though they are separated during crystallization into an each lamellar crystal. These morphological studies would also support good miscibility between linear and branched polyethylenes.

From the above investigations, it is considered that the reductions of the crystallization rate and spherulite size of linear polyethylene caused by the addition of a small amount HP-LD result in the decrease of crystallization-induced surface roughness of a blown film, and thus be the origin of the improvement effect of blending HP-LD on the optical properties of L-LD. The increase of haze and decrease of gloss with increase of HPLD (Figure 1) may be due to the fact that the die-flow-induced surface roughness becomes dominant with increasing HP-LD. ${ }^{2,3}$

\section{CONCLUSIONS}

To elucidate the origin of the improvement effect of polyethylene blends in various practical polyethylene manufacturings, some basic approaches were tried for the blends of linearand branched-polyethylenes.

1. Melt viscoelastic properties were measured for linear/linear, branched/branched, and linear/branched polyethylene blends. Among the various parameters elastic ones such as $G^{\prime}$ and $P_{11}-P_{22}$, especially of linear/branched polyethylene blends, have a large positive dependence on blend composition and do not obey the following mixing rule which is valid for both linear/linear and branched/branched polyethylene blends at a constant shear rate,

$$
P_{\mathrm{b}}^{0.4}=w_{1} P_{1}^{0.4}+w_{2} P_{2}^{0.4}
$$

where $P$ is $G^{\prime}$ or $P_{11}-P_{22}, w$ the weight faction, and subscripts $b, 1$, and 2 stand for the blend, component polymer 1 and 2 , respectively. The degree of deviation from the above mixing rule is sensitively dependent on shear rate for linear/branched polyethylene blends.

2. From the Flory-Huggins interaction parameter, $\chi_{12}$, which is calculated from equilibrium melting temperature depression, the blend of linear- and branched-polyethylene is considered to be miscible and the degree of miscibility is the same as the linear/linear system. The rate of isothermal crystallization and spherulite size of linear polyethylene are remarkably reduced by mixing a small amount of HP-LD.

3. It has become apparent from SEM and TEM analyses that linear- and branchedpolyethylenes in solid state are well mixed in sub-micron order though they make their individual lamellar crystals.

Acknowledgments. We wish to thank Mr. K. Kojima for his experimental assistance in the electron microscopic study and $\mathrm{Mr}$. Y. Sato for GPS-LALLS measurements. Thanks are also due to Sumitomo Chemical Co., Ltd. for permission to publish this paper.

\section{REFERENCES}

1. T. Kanai and J. L. White, Polym. Eng. Sci., 24, 1185 (1984).

2. H. Ashizawa, J. E. Spruil, and J. L. White, Polym. Eng. Sci., 24, 1035 (1984).

3. M. Rokudai, S. Fujimoto, Y. Yasuda, and Y. Kanesige, Toyosoda Kenkyu Houkoku, 28, 83 (1984).

4. E. E. Drott and R. A. Mendelson, J. Polym. Sci., A2, 8, 1361 (1970).

5. S. Shiga, Nippon Gomu Kyokaishi, 59, 162 (1986).

6. G. Kanig, Prog. Colloid Polym. Sci., 57, 176 (1975).

7. H. Yamane and J. L. White, Nihon Reoroji Gakkaishi, 15, 87 (1987).

8. M. K. Badr and C. I. Chung, ANTEC '85, 918 (1985).

9. I. H. J. Radusch, Plaste Kautsch., 31, 262 (1984).

10. M. S. Jaćović, D. Pollock, and R. S. Porter, J. Appl. Polym. Sci., 23, 517 (1979).

11. M. M. Dumoulin, L. A. Utracki, and J. Lara, Polym. Eng. Sci., 24, 117 (1984).

12. S. F. Christov, I. I. Skorokhodov, and Z. V. Shuraleva, Vysokomol. Soedin. Ser., A, 20, 1699 (1978).

13. Y. Gotoh, Y. Naito, and T. Konaka, Polym. Prepr. Jpn., 36, 1269 (1987). 


\section{S. HosodA and Y. GoTOH}

14. D. R. Norton and A. Keller, J. Mater. Sci., 19, 447 (1984).

15. G. Michler, H. Steinbach, and K. Hoffmann, Acta Polym., 37, 389 (1986).

16. P. Smith and R. St. Manley, Macromolecules, 12, 483 (1979).

17. N. K. Datta and A. W. Birley, Plast. Rubber Chem. Appl., 2, 237 (1982)

18. M. Slaweyko, M. Martin, and H. Klaus, Plaste
Kautsch., 30, 682 (1983).

19. G. H. Edward, Br. Polym. J., 18, 88 (1986).

20. F. P. La Mantia and D. Acierno, Eur. Polym. J., 21, 811 (1985).

21. T. Nishi and T. T. Wang, Macromolecules, 8, 909 (1975).

22. S. Hosoda, K. Kojima, and M. Furuta, Makromol. Chem., 187, 1501 (1986). 